\title{
38
}

\section{Quality learning through computer conferencing}

\author{
Roger Austin \\ University of Ulster \\ Coleraine \\ Northern Ireland
}

\begin{abstract}
Relatively little work has been done on the use of computer conferencing with older school or college students. This paper will report on a project carried out in 1993-1994 which involved 16-18 year old students training to be history teachers and historical experts. The students participated in a computer conference on twentieth century history and exchanged views with 'experts' on the 'Origins of the First World War' and on 'Ireland and Great Britain 19121923'. Evaluation showed sustained preparation, more group work, greater class discussion than normal and improvement in the quality of writing. Also the various roles which the experts played, and evidence on how teachers are managing to integrate conferencing into their normal teaching will be discussed.
\end{abstract}

Main conference themes: flexible learning, distance learning, integration, teacher education

Educational areas: secondary education, further education, higher education

Study topics: humanities/social sciences

Secondary keywords: case studies, classroom practice, communication, curriculum development, teleconferencing 


\section{INTRODUCTION}

Although Computer Mediated Conferencing (CMC) has been used quite extensively in Higher Education [1], there are virtually no examples of its application in pre-university work. In many ways this is surprising since the potential of CMC for exchanging informed views on a wide range of topics has been recognized for some time. This paper is based on computer conferences run in 1993-1994 using the electronic mail system Campus 2000 [2]. The purpose behind the conferences was to introduce teacher trainee students of history, school students taking history at an advanced level, their teachers and historical 'experts' to the idea of a 'community of learning'.

In the first instance the conference ran for a month in 1993 and then with new questions for a six month period from January to June 1994. Analysis of the transcript of the conference interviews with teacher trainee students and a questionnaire submitted to a sample of conference participants produced data on the learning benefits to students, the role of experts in CMC and the management of student learning.

\section{LEARNING OUTCOMES FOR STUDENTS}

\section{Background preparation}

Students said that it encouraged them to do background preparation related to the topics in the conference. The fact that their contributions to the conference are identified by the name of the school or college, may put gentle pressure on them to ensure that their opinions are well-founded. Unlike a face-to-face sixth form conference or even a class debate where any discussion will be verbal, the written nature of $\mathrm{CMC}$ demands greater deliberation. Furthermore, although it is possible for participants to amend, edit or delete their own comments, views expressed in the conference are likely to remain 'on the record' for public scrutiny over a period of anything from one to six months. Teachers are also fairly conscious of the way in which their students' comments may reflect on the school, but they report that they are able to resist the urge to censor or improve the views of their students.

A good example of the preparation which students carried out, is the following. The history specialist gave the students a condensed excerpt from Roy Foster's Modern Ireland 1600-1972 and invited them to evaluate Foster's views on the extent of popular support for the IRA in 1919-1921. It was a question which prompted students in two schools in Northern Ireland to write a detailed analysis based on very close reading of Foster and other historians. While this sort of work could take place in any normal classroom without the 
stimulus of computer conferencing, evidence from the teachers concerned suggests that $\mathrm{CMC}$ acted as an incentive and as a clear goal for purposeful reading.

The two schools came from different traditions in Northern Ireland and the topic they were debating had a powerful link with the contemporary political situation in Ulster. We shall return in due course to the question of how CMC can provide a forum for the discussion of controversial issues.

\section{CMC as stimulus for structuring understanding}

CMC allows contributions to be as short or as long as the participant chooses and we have had examples of the memorable one liner 'Does anyone blame Serbia?' in a discussion on responsibility for the outbreak of the First World War, but also detailed three page responses. In general, since a conference is concerned with discourse implying an open sharing of views and ideas, contributions are often between half a page and a page. For students this means a form of writing rather different to the normal advanced level essay and since the medium is a semi-public one, there is little or no scope for padding or comments which do not relate specifically to the question. In short CMC demands input which is relevant, succinct and supported by evidence.

This type of writing involves a sort of synthesis where students are distilling their understanding and presenting it in a shortened format. Teachers felt this was a useful exercise for training the students to summarize complex arguments.

\section{CMC provokes debate and discussion between members of the class}

Some history teachers say that it is difficult to generate discussion in advanced level classes, either because the students do not know enough or because they are unfamiliar with the nature of discussion at such a level. Debate normally hinges on differences of interpretation, discussion over the relative importance of different factors in explaining an aspect of the past or measuring the significance of an individual or a trend in a particular period.

The evidence from both teacher trainees, teachers and students is that $\mathrm{CMC}$ provokes considerable interaction within a class and that it does this particularly well when students are working in groups of 3 or 4 with the responsibility for answering an item in the conference. The students are evidently stimulated into discussion by the opinions of other students-one teacher commented that when he gave his class a print-out of the responses which had already been entered in the conference, several members of the class said 'Well that's not right for a start!' Another said that the prospect of communicating their understanding of the issue created a highly charged and purposeful classroom atmosphere. 
The second reason for group discussion is that the students have to try to agree on a response which will be subject to the scrutiny of their peers, both within the class and in a wider, unknown audience. This audience will include a specialist in the subject and probably young people in their own country and abroad. For all these reasons students feel the need to exchange their views verbally within their own working group and then with the class as a whole before they prepare their response on a wordprocessor. At any point in this process views can be modified or amplified. There are some indications that this higher level of purposeful interaction is leading to deeper understanding.

\section{CMC leads to greater participation in class work}

In the evaluation data which was collected from the history conference, there was evidence to suggest that $\mathrm{CMC}$ was an attractive alternative for some students who were not very willing contributors to normal classroom discussion. The reasons for this appear to lie in the nature of human and computer interaction. Some students who are reticent about taking part in class discussion, may be reluctant because they are badly prepared, because they are shy or because they are anxious about the reaction of their peers to what they want to say. In some cases students who are not quick enough or confident enough about their views to discuss things in class, find that conferencing gives them the time to prepare what they want to say. And also the fact that the 'audience' for their views is not immediately visible, seems to reassure them. It may be that the experience of participating in a conference of this sort actually improves student confidence in general and increases the likelihood of them playing a more assertive role in normal class discussion. Although the questionnaire data is not conclusive on this last point, it is clear that more students participate more of the time in a computer conference than at most other times.

\section{CMC leads to a higher quality of written work than is normally produced in class}

The contention that students write more effectively in a computer conference than in normal class assignments is based on the judgement of participating teachers. It is an unexpected outcome which requires both explanation and illustration. Why should students write better in a computer conference? There are at least three reasons for such a finding. The first is that students indicated in the questionnaire that they found CMC increased their level of interest and motivation in the topics under study. While motivation is not a guarantee for quality written work, it is an important factor for many students. Secondly the sense of 'audience' is certainly at work here. Educationists have noted from infant school onwards how important it is for students to have their 
work displayed in the classroom. It is a curious feature of post-16 education that the opportunities for such displays are often restricted to students working in the visual or performing arts. What opportunities are there for young people in the humanities part of the curriculum to present their understanding, their knowledge and their skills in a public arena?

Where a conference is well run with responses being reacted to promptly by specialists or other participants, it is clear that students have a keen sense that they are taking part in a debate, are anxious for feedback and are extremely interested in knowing what impact their views have made on others. In other words they are sharply aware of the difference between an assignment for the teacher, a rather private test of their understanding and the more public demonstration of their knowledge which is demanded in CMC. In some ways the latter is perceived to have more intrinsic value, perhaps because at this level the students are already becoming aware that one important part of historical discourse is a public debate between students of history on the relative strengths of the case they are putting forward. What distinguishes computer conferencing from any other form of discourse is the opportunity for students, teachers and historians to place their opinions on record over an agreed period of time. Their comments are open to confirmation and challenge from any quarter. The nature of the medium contributes to the sense that all parties involved are engaged in a common, cooperative purpose: a search for the most convincing explanation of past human behaviour.

In a discussion of which state was most responsible for the outbreak of the First World War contributions came from students in Northern Ireland, the Republic of Ireland, France, England, Scotland and Germany. What their contributions showed is that students write at length, they write with confidence and the substance of what they expressed is marked by a careful and balanced appraisal of the options open to each of the countries involved in the outbreak of war. In addition to the factors we have noted in explaining such quality, sense of audience and motivation, there is a third element. CMC does not of itself guarantee a high level of interaction and conferences on other topics for 16-18 year old students have not generated the same level of discourse. The fact that useful comments were made in this particular conference is almost certainly because the topics were central to the students' examination courses, the questions were seen to be relevant and the participants had the certainty that their views would be read and reacted to by historians and by other students. In other words, teachers and students could regard the time spent on CMC as extending what they had to do anyway, while at the same time giving them a unique forum to test out their knowledge against the opinions of specialists and peers. The claim that students write better in a computer conference than in normal class assignments evidently springs from 
harnessing the communicative and participatory power of $\mathrm{CMC}$ to the perceived demands of the syllabus.

It is worth making one further point at this stage arising from the students' comments. There were some attempts in the students' responses to come to terms with the nature of CMC and in particular to weave in comments which explicitly refer to the views expressed by other participants. Searching for the right kind of language to register disagreement is no easy task when the medium of CMC denies contributors the chance to use body language or tone of voice to express nuances of meaning. When all meaning is carried in the written text, the choice of language to show dissent has to be chosen with care. Since interaction with other students lies at the very heart of CMC, teachers may need to give students guidance in this relatively new medium for written expression.

\section{CMC brings into play the perspectives of students from other cultures and countries}

One of the greatest benefits of CMC is the way it can bring together hugely diverse groups of people who are meeting in what journalists call 'cyberspace'. When we first approached people to ask if they wanted to take part in a computer conference, they often asked us where the conference was being held and were rather taken aback to be told that it was in their own schooland in the schools of some 70-80 other participants. The idea that a real debate can take place across countries and can span a period of time lasting from a month to six months, requires a big imaginative leap. Our evidence suggests that students and teachers are excited by this novel form of world-wide communication and that they see it opening up horizons otherwise unthought of.

One of the most obvious examples from the recent conference was the way in which students from several European countries were all able to share ideas on the origins of the First World War. To have set up a face-to-face conference on such a topic would have involved huge expense, enormous organization and far greater input of time than $\mathrm{CMC}$ requires. Furthermore all the participants in the computer conference leave with a transcript of the entire discussion and time to get the gist of views expressed in languages other than their own.

Sceptics might ask if this is all really necessary. Why should students in the British Isles need to know what students in continental Europe think about the First World War or for that matter, the French Revolution, the rise of National Socialism or any other European or world historical issue? There are at least three possible answers to this; one is pragmatic, one relates to the 
epistemological character of history and the third is a philosophical and moral perspective.

The pragmatic reason is that an awareness of other, possibly continental interpretations can help to either confirm students' understanding or cause a re-think. In either case the students have to go through a process of clarifying their understanding and this will take place through further classroom discussion, further reading and personal reflection. Quite apart from the learning benefits to their students some teachers saw CMC as a practical way of incorporating IT and a European dimension in their history work.

The second reason for arguing that students should be aware of the opinions of others is that it can sharpen their appreciation of what it means to 'do history'. Historical discourse in 'democratic' states is an open and public affair where historians research, publish and use the convention of footnotes to indicate the evidence upon which they have drawn their conclusions. Books and articles are then subject to peer group evaluation through published reviews. Increasingly this process takes place in a European and global context where historians assume that their writing will often address an audience beyond their national frontiers. In a quite dramatic way $\mathrm{CMC}$ replicates this process by expecting that participants will make clear the basis for their views - and if they do not they, should be ready to be challenged on this in the conference.

Thirdly student discussion on the validity of 'revisionist' interpretations of Irish history not only highlights the way in which the students are inducted into the world of professional discourse with trainee history teachers and specialists, but it brings out the moral and philosophical justification for using CMC. Prejudices about other groups, whether they are Irish, British, French, German or whatever, are more difficult to sustain in the context of an exchange of informed and publicly presented views. The legitimacy of a position is based on a scrupulous regard for the quality of the argument advanced and the evidence on which it is based. Since participants cannot physically see each other they cannot judge the other contributors by their appearance, clothes or accent but only on what they write. Evidence from the teachers and students who took part in the conference, suggests that contact of this sort is highly rewarding, particularly when the balance in the activity between competition and cooperation leans to the latter.

Finally, it is important to note that CMC in Northern Ireland enables young people to discuss historical questions which have a powerful contemporary feel to them. Conferencing lets students talk to each other from the safety of their own 'territory', but in a semipublic forum where they have to go beyond a simple exchange of greetings to a level where they are investigating how different perceptions of the past can exist. Although 'Education for Mutual 
Understanding' (EMU), one of the crosscurricular themes in Northern Ireland's Common Curriculum, is not a legal requirement after 16, many schools welcome appropriate means of addressing EMU throughout the school. CMC opens up new channels for this sort of work both within Northern Ireland, in the island of Ireland and across Europe [3].

\section{CONCLUSION}

The focus of this paper has been on the impact of CMC on quality learning. The evidence from the history conference indicates that where conferences are well managed and with expert contribution [4], there are real benefits both for older students in school and for trainee teachers. There would appear to be no reason why the model of conferencing described in this paper could not be extended to other subject areas in school, to other age groups [5] and to the higher education sector. The case for $\mathrm{CMC}$ on a cost-benefit analysis looks strong; large numbers of participants can join in global discourse at relatively little cost using a medium which motivates and improves learning.

\section{REFERENCES}

1. Mason, R. (ed) (1993) Computer Conferencing, The Last Word. Beach Holme Publishers.

2. Campus 2000 can be contacted at Network House, Brindley Way, Hemel Hempstead HP3 9RR.

3. Austin, R. (1994) Computer conferencing; a channel for North-South dialogue. Oideas.

4. For a fuller discussion of the role of experts and the management of computer conferencing in schools, see Roger Austin, Computer Conferencing in History, Historical Association, Occasional Paper 11, March 1995.

5. History teacher trainee students in Northern Ireland are currently exploring the role of CMC with school students aged 13-16. 